Sophie Gouverneur, Prudence et subversion libertines. La critique de la raison d'État chez François de La Mothe Le Vayer, Gabriel Naudé et Samuel Sorbière

\title{
Grazia Lana
}

\section{(2) OpenEdition \\ 1 Journals}

Edizione digitale

URL: https://journals.openedition.org/studifrancesi/26213

DOI: $10.4000 /$ studifrancesi.26213

ISSN: 2421-5856

\section{Editore}

Rosenberg \& Sellier

\section{Edizione cartacea}

Data di pubblicazione: 1 avril 2007

Paginazione: 172

ISSN: 0039-2944

\section{Notizia bibliografica digitale}

Grazia Lana, «Sophie Gouverneur, Prudence et subversion libertines. La critique de la raison d'État chez François de La Mothe Le Vayer, Gabriel Naudé et Samuel Sorbière», Studi Francesi [Online], 151 (LI | I) | 2007, online dal 30 novembre 2015, consultato il 23 novembre 2021. URL: http://

journals.openedition.org/studifrancesi/26213 ; DOI: https://doi.org/10.4000/studifrancesi.26213

Questo documento è stato generato automaticamente il 23 novembre 2021.

\section{cc) $(8)$}

Studi Francesi è distribuita con Licenza Creative Commons Attribuzione - Non commerciale - Non opere derivate 4.0 Internazionale. 


\title{
Sophie Gouverneur, Prudence et
} subversion libertines. La critique de la raison d'État chez François de La Mothe Le Vayer, Gabriel Naudé et Samuel Sorbière

\author{
Grazia Lana
}

\section{NOTIZIA}

SOPHIE GOUVERNEUR, Prudence et subversion libertines. La critique de la raison d'État chez François de La Mothe Le Vayer, Gabriel Naudé et Samuel Sorbière, Paris, Champion, 2005, pp. 532.

1 Con questo studio, Sophie Gouverneur si propone di mettere in relazione una ricerca di filosofia generale sulla nozione di prudenza con una ricerca in storia della filosofia sul libertinaggio francese del xviI secolo, analizzando le opere di François de La Mothe Le Vayer, Gabriel Naudé e Samuel Sorbière.

2 Sull'onda di una rivalutazione filosofica dei libertini, oggetto del lavoro è di dimostrare che il pensiero libertino si presenta come una filosofia completa e coerente, benché non sistematica, articolata intorno alla dissimulazione, intesa non come semplice ipocrisia ma come un oggetto teorico e pratico filosoficamente essenziale.

Gli autori libertini sono stati inseriti fino ad ora solo nella storia letteraria che si è limitata a fare in realtà una storia ideologica di costumi ed ha contribuito a rinforzare lo sfaldamento, anacronistico nel xvII secolo, tra letteratura e filosofia, negando al libertinaggio ogni interesse teorico. 
4 L'analisi degli scritti dei tre autori presi in esame dimostra come essi propongano una riflessione politicamente sovversiva, anche se solo letteraria, concepita a partire dalla loro pratica della prudenza. La loro azione letteraria e filosofica non vuole portare a turbamenti politici o a lotte contro l'ordine stabilito, ma tende ad illuminare le menti sui limiti di un certo tipo di politica. Solo la comprensione dei tre aspetti nei quali la prudenza è successivamente analizzata (politica prudenziale, etica prudenziale ed estetica prudenziale) e delle loro articolazioni permette di capire la posizione politica di questi libertini e come può manifestarsi un pensiero politico sovversivo, in un periodo di assolutismo e di repressione, dal quale non si può evidentemente esigere che proclami apertamente le sue tesi.

5 La riflessione politica riprende il tema della "ragion di stato" che i tre autori intendono sia in senso machiavellico di un'arte dell'inganno (dominante in Naudé), sia in un senso più civile di un'arte di governare fondata sulla ricerca del minor male nella sua compatibilità con la morale (senso dominante in Le Vayer e Sorbière).

6 Lo studio è diviso in due parti: nella prima («Des philosophes au service du pouvoir?») è trattato il tema dell'antropologia della dissimulazione e comprende un'analisi e giustificazione della politica prudenziale. Nella seconda («Dénouer la servitude») sono trattate l'etica prudenziale e l'estetica prudenziale.

7 Infine il tema della dissimulazione, oltre a quello dell'"obbedienza distanziata" e della sovversione, pare all'autrice essenziale per comprendere i legami tra scetticismo e libertinaggio dei quali permette di mostrare le affinità e le divergenze.

8 Chiudono il volume 1) una sezione dedicata a cenni biografici dei tre autori; 2) una ricca bibliografia divisa in due grandi settori: il primo comprende le opere degli autori presi in esame, gli studi critici ad essi dedicati ed un corpus di fonti sulla prudenza cui i libertini si rifanno con bibliografia inerente; al secondo settore è riservata una bibliografia tematica; 3) un indice dei nomi; 4) una Table des matières molto dettagliata che fornisce una chiara sintesi dei temi trattati. 